\title{
A Good Practice Guide to the Administration of Substances and Removal of Blood, Including Routes and Volumes
}

\author{
Karl-Heinz Diehl' ${ }^{1}$, Robin Hull ${ }^{2}$, David Morton ${ }^{3}$, Rudolf Pfister ${ }^{4}$, Yvon Rabemampianina ${ }^{5}$, \\ David Smith,*, Jean-Marc Vidal ${ }^{7}$ and Cor van de Vorstenbosch ${ }^{8}$ \\ ${ }^{1}$ Aventis, PO Box 1140, D35001 Marburg, Germany \\ ${ }^{2}$ N I B S C, Blanch Lane, South Miimms, Potters Bar, Hertfordshire EN6 3QG \\ ${ }^{3}$ The University of Birmingham, Medical School, Edgbaston, Birmingham B15 2TT \\ ${ }^{4}$ Novartis Pharma AG, CH-4002 Basel, Switzerland \\ ${ }^{5}$ Centre de Recherche Pfizer, Etablissement d'Amboise, Z1 Pocé-sur-Cisse-BP 15937401 Amboise Cedex, France \\ ${ }^{6}$ AstraZeneca R\&D Charnwood, Bakewell Road, Loughborough, Leics LE11 5RH \\ ${ }^{7}$ Aventis, 102 Route de Noisy, 95235 Romainville Cédex, France \\ ${ }^{8} \mathrm{~N}$ V Organon, PO Box 20, 5340 BH Oss, Netherlands
}

Key words: blood volumes; blood removal; administration substances; laboratory animals; refinement.

This article is the result of an initiative between the European Federation of Pharmaceutical Industries Associations (EFPIA) and the European Centre for the Validation of Alternative Methods (ECVAM). Its objectives are to provide the researcher in the safety evaluation laboratory with an up-to-date, easyto-use set of data sheets to aid in the study design process whilst at the same time affording maximum welfare considerations to the experimental animals.

Although this article is targeted at researchers in the European Pharmaceutical Industry, it is considered that the principles underpinning the data sets and refinement proposals are equally applicable to all those who use these techniques on animals in their research, whether in research institutes, universities or other sectors of industry. The implications of this article may lead to discussion with regulators, such as those responsible for pharmacopoeial testing.

There are numerous publications dealing with the administration of test substances and the removal of blood samples, and many laboratories also have their own 'in-house' guidelines that have been developed by custom and practice over many years. Within European Union Directive 86/609EEC ${ }^{1}$ we have an obligation to refine experiments to cause the minimum amount of stress. We hope that this article will provide background data useful to those responsible for protocol design and review.

This guide is based on peer-reviewed publications whenever possible, but where this is not possible we have used 'in-house' data and the experience of those on the working party (as well as helpful comments submitted by the industry) for a final opinion. The guide also addresses the continuing need to refine the techniques associated with the administration of substances and the withdrawal of blood, and suggests ways of doing so. Data-sharing between laboratories should be encouraged to avoid duplication of animal work, as well as sharing practical skills concerning animal welfare and scientific problems caused by 'overdosing' in some way or another. The recommendations in this guide refer to the 'normal' animal, and special consideration is needed, for instance, during pregnancy and lactation. Interpretation of studies may be confounded when large volumes are administered or excessive sampling employed, particularly if anaesthetics are used. Copyright (c) 2001 John Wiley \& Sons, Ltd.

\section{GOOD PRACTICE GUIDE FOR}

\section{ADMINISTRATION OF SUBSTANCES}

\section{Introduction}

Dosing of experimental animals is necessary for a variety of scientific investigations and to meet regulat-

\footnotetext{
* Correspondence to: Dr David Smith, Senior Director, Toxicology, AstraZeneca, R\&D Charnwood, Bakewell Road, Loughborough LE11 5RH
}

ory demands. The pharmaceutical industry, in particular, has investigated the levels of dosing compatible with animal welfare and valid science. ${ }^{2}$ In the preclinical stage of the safety evaluation of new drugs it is normal practice to use multiples of the 'effective dose' in order to attempt to establish the necessary safety margins. Where chemicals are of low toxicity or are only poorly soluble in acceptable formulations, a large volume may be required to be given to individual animals to satisfy both scientific and regulatory requirements. The intended clinical use may also have an impact on the acceptability of larger than usual dose volumes, e.g. imaging agents or plasma expanders for intravenous application. 
The objectives of the Technical Sub group of EFPIA/ ECVAM were as follows:

(i) to provide a guide on administration volumes for use in common laboratory species used in toxicity studies required by regulatory authorities;

(ii) to provide consensus dosage levels for routine use that represent good practice in terms of animal welfare and practicality;

(iii) to produce a guide to dosage levels representing the upper limit of common practice, which leaves scope to make the case for special investigations.

\section{Administration volumes}

Table 1 presents administration volumes for the commonly employed routes in the most frequently used species. They are consensus figures based on published literature and internal guidelines. The marmoset and minipig are now considered within this category because they are being used increasingly in Europe.

Two sets of values are shown in each column: values on the left are intended as a guide to 'good practice' dose volumes for single or multiple dosing; values on the right, where given, are the possible maximal values. If maximal values are exceeded, animal welfare or scientific implications may result and reference to the responsible veterinary surgeon should be made. In some instances values are there to accommodate pharmacopoeial requirements.

Some of these suggested maximum values have been obtained from recent literature,,$^{3,4}$ but appear high when compared with 'good practice' values. The need for careful attention to animal welfare and the formulation of material used at high dose volumes are emphasized, particularly if repeat dosing is intended. Study duration could be restricted and scientific validity compromised by physiological reaction to high dose volumes. It is therefore essential from an ethical standpoint that these issues are fully considered, e.g. by inspectorate or ethical committee, before protocols are finalized and work commences. It is also strongly recommended for ethical as well as scientific reasons that physicochemical compatibility studies (in vitro) and smallscale pilot studies (small groups of animals) are carried out on any new formulation before committing to larger scale studies. Dose volumes should be the minimum compatible with compound formulation and accuracy of administration.

\section{Administrative routes}

Oral route. On occasions, it may be necessary to restrict the animals' food intake before dosing. This factor may affect absorption. Large dose volumes $\left(40 \mathrm{ml} \mathrm{kg}^{-1}\right)$ have been shown to overload the stomach capacity and pass immediately into the small bowel. ${ }^{5}$ Larger volumes may also reflux into the oesophagus. The duration of fasting will depend upon the feeding pattern of the species, the starting time for food restriction, the physiology of the species, the length of time of dosing, diet and the light cycle. ${ }^{6}$ It is recommended that for accuracy of dosing and to avoid dosing accidents liquids are administered by gavage.

Parenteral routes. For substances administered parenterally, the dose volume used, stability of the formulation before and after administration, $\mathrm{pH}$, viscosity, osmolality, buffering capacity, sterility and biocompatibility of the formulation are factors to consider. This is particularly important for multiple dose studies. These factors are reviewed in some detail by Claassen. ${ }^{7}$ The smallest needle size should be used, taking into account the dose volume, viscosity of injection material, speed of injection and species.

Subcutaneous. This route is frequently used. The rate and extent of absorption depend on the formulation.

Intraperitoneal. This route is used infrequently for multiple dose studies because of possible complications. There is a possibility of injecting into the intestinal tract and irritant materials may cause peritonitis. Drug absorption from the peritoneal cavity after the administration of the compound as a suspension is dependent on the properties of the drug particles and the vehicle, and the drug may be absorbed into both systemic and portal circulations.

Intramuscular. Intramuscular injections may be painful because muscle fibres are necessarily placed under

Table 1. Administration volumes considered good practice (and possible maximal dose volumes)

Species

\begin{tabular}{lr}
\cline { 2 - 2 } & Oral \\
Mouse & $10(50)$ \\
Rat & $10(40)$ \\
Rabbit & $10(15)$ \\
Dog & $5(15)$ \\
Macaque & $5(15)$ \\
Marmoset & $10(15)$ \\
Minipig & $10(15)$
\end{tabular}

Route and volumes $\left(\mathrm{ml} \mathrm{kg}^{-1}\right)$

\begin{tabular}{|c|c|c|c|}
\hline i.p. & i.m. & i.v. (bolus) & i.v. (slow inj.) \\
\hline $20(80)$ & $0.05^{\mathrm{b}}(0.1)^{\mathrm{b}}$ & 5 & (25) \\
\hline $10(20)$ & $0.1^{\mathrm{b}} \quad(0.2)^{\mathrm{b}}$ & 5 & (20) \\
\hline $5(20)$ & $0.25 \quad(0.5)$ & 2 & $(10)$ \\
\hline $1(20)$ & $0.25 \quad(0.5)$ & 2.5 & (5) \\
\hline c (10) & $0.25 \quad(0.5)$ & 2 & c \\
\hline c (20) & $0.25 \quad(0.5)$ & 2.5 & (10) \\
\hline (20) & $0.25 \quad(0.5)$ & 2.5 & (5) \\
\hline
\end{tabular}

aFor non-aqueous injectates, consideration must be given to time of absorption before re-dosing. No more than two intramuscular sites should be used per day. Subcutaneous sites should be limited to two or three sites per day. The subcutaneous site does not include Freund's adjuvant administration.

balues in millilitres per site.

'Data not available. 
tension by the injected material. Sites need to be chosen to minimize the possibility of nerve damage. Sites should be rotated for multiple dose studies. A distinction needs to be made between aqueous and oily formulations when speed of absorption is important (oily formulations are likely to remain as a depot for $>24 \mathrm{~h}$ ). With multiple dose studies there is a need to consider the occurrence of inflammation and its sequelae.

Intravenous administration. For this route, distinctions are made between bolus injection, slow intravenous injection and intravenous infusion. The values in Table 1 relate to bolus injection and slow intravenous injection.

(i) Bolus injection. In most studies using the intravenous route the test substance is given over a short period of approximately $1 \mathrm{~min}$. Such relatively rapid injections require the test substance to be compatible with blood and not too viscous. When large volumes are required to be given, the injection material should be warmed to body temperature. The rate of injection is an important factor in intravenous administration and it is suggested that, for rodents, the rate should not exceed $3 \mathrm{ml} \mathrm{min}{ }^{-1}$. No detectable changes in haematocrit or heart rate were observed in dogs following rapid intravenous injection of $6 \mathrm{ml} \mathrm{kg}^{-1}$ saline, but $20 \mathrm{ml} \mathrm{kg}^{-1}$ was associated with $15 \%$ haemodilution and a transient tachycardia (up $46 \%$ over $1 \mathrm{~min}) .^{8}$

(ii) Slow intravenous injection. Because of the expected clinical application of the compound, or because of limiting factors such as solubility or irritancy, it may be necessary to consider administering substances by slow intravenous injection. Typically, different techniques would be applied for slow injection to minimize the possibility of extravascular injection of material. For slow intravenous injection over the course of 5-10 min a standard or butterfly needle might be used, or better still an intravenous cannula may be taped in place in a superficial vein (short term), or surgically placed some time prior to use (longer term or multiple injections).

It has been shown that rats may be given daily intravenous injections of isotonic saline at dosages up to $80 \mathrm{ml} \mathrm{kg}^{-1}$ at $1 \mathrm{ml} \mathrm{min}^{-1}$ for 4 days without significant signs of distress or pulmonary lesions. ${ }^{9}$ However, pulmonary lesions increased in incidence and severity when the duration of treatment increased to 30 days and the injection was administered at either $0.25,0.5$ or $1.0 \mathrm{ml} \mathrm{min}{ }^{-1} .{ }^{10}$ There may well have been adverse effects at an earlier time point but the pathology had not had time to develop.

(iii) Continuous infusion. For similar reasons of solubility or clinical indication it may be necessary to consider continuous infusion, but careful consideration is needed if infusions are prolonged. The volume and rate of administration will depend on the substance being given and take account of fluid therapy practice. As a guide, the volume administered on a single occasion will be $<10 \%$ of the circulating blood volume over $2 \mathrm{~h}$.
Information on circulating blood volumes is available in Table 3. Minimal effective restraint of animals with least stress is a key factor to consider for prolonged infusions.

The total duration of an infusion is also a factor. Table 2 presents recommended dose rates and volumes for discontinuous ( $4 \mathrm{~h}$ per day) and continuous $(24 \mathrm{~h}$ ) infusion. (Further data are required to complete this table.)

Volumes and rates for the rabbit are based on data derived from embryotoxicity studies, which showed no effects on the foetus but perivascular granular leucocyte cuffing and proliferative endocarditis in dams receiving $\geqslant 2 \mathrm{ml} \mathrm{kg}^{-1} \mathrm{~h}^{-1}$. ${ }^{11}$ Infusion rates in rats are typically in the range $1-4 \mathrm{ml} \mathrm{kg}^{-1} \mathrm{~h}^{-1},{ }^{12-14}$ but ideally should not exceed $2 \mathrm{ml} \mathrm{kg}^{-1} \mathrm{~h}^{-1}$ in embryotoxicity studies. Values for the mouse, ${ }^{15}$ dog and macaque ${ }^{16}$ and minipig (unpublished data) are based on repeated dose studies of 1 month in duration.

Other limits, indicating the importance of the vehicle formulation at high dose volumes, are highlighted in four publications. ${ }^{17-20}$ These data indicate that there are large differences in tolerated volume by i.v. infusion, dependent upon the vehicle used. The long-term effects on other physiological systems have not been investigated.

Intradermal. This site is typically used for assessment of immune, inflammatory or sensitization response. ${ }^{21,22}$ Material may be formulated with an adjuvant. Volumes of $0.05-0.1 \mathrm{ml}$ can be used, dependent upon the thickness of the skin.

\section{Vehicles for administration}

Vehicle selection is an important consideration in all animal investigations. Vehicles themselves should offer optimal exposure but should not influence the results obtained for the compound under investigation, and as such they should ideally be biologically inert, have no effect on the biophysical properties of the compound and have no toxic effects on the animals. If a component of the vehicle has biological effects, the dose should be limited such that these effects are minimized or not produced. Simple vehicles used to administer compounds include aqueous isotonic solutions, buffered solutions, co-solvent systems, suspensions and oils. For non-aqueous injectates, consideration should be given for time of absorption before re-dosing. When administering suspensions the viscosity, $\mathrm{pH}$ and osmolality of the material need to be considered. The use of cosolvent systems needs careful attention because the vehicles themselves have dose-limiting toxicity. Laboratories are encouraged to develop a strategy to facilitate selection of the most appropriate vehicle based on the animal study being performed and the properties of the substance under investigation.

\section{GOOD PRACTICE GUIDE FOR BLOOD SAMPLING}

\section{Introduction}

Blood removal is one of the most common procedures performed on laboratory animals and methods for lab- 
Table 2. Repeated intravenous infusion: dose volumes/rates (and possible maximal volumes/rates) ${ }^{\mathrm{a}}$

\begin{tabular}{|c|c|c|c|c|c|c|}
\hline Daily infusion period & Mouse & Rat & Rabbit $^{\mathrm{b}}$ & Dog & Macaque & Minipig \\
\hline \multicolumn{7}{|l|}{$\begin{array}{l}\text { Total daily volume } \\
\left(\mathrm{ml} \mathrm{kg}^{-1}\right)\end{array}$} \\
\hline $4 \mathrm{hL}^{\mathrm{c}}$ & $\mathrm{L}^{\mathrm{c}}$ & 20 & $\mathrm{~L}^{\mathrm{c}}$ & 20 & $\mathrm{~L}^{\mathrm{c}}$ & $\mathrm{L}^{\mathrm{c}}$ \\
\hline $24 \mathrm{~h}$ & $96(192)$ & $60(96)$ & $24(72)$ & $24(96)$ & 60 & 24 \\
\hline \multicolumn{7}{|l|}{ Rate $\left(m / k^{-1} h^{-1}\right)$} \\
\hline $4 \mathrm{~h}$ & $\mathrm{~L}^{\mathrm{c}}$ & 5 & $\mathrm{~L}^{\mathrm{c}}$ & 5 & $\mathrm{~L}^{\mathrm{c}}$ & $\mathrm{L}^{\mathrm{c}}$ \\
\hline $24 \mathrm{~h}$ & $4(8)$ & $2.5(4)$ & $1(3)$ & $1(4)$ & 2.5 & 1 \\
\hline
\end{tabular}

oratory mammals and birds were reviewed in the first report of the BVA/FRAME/RSPCA/UFAW Joint Working Group on Refinement. ${ }^{23}$ This current article aims to provide an easy-to-use guide based on the latest available information, and addresses the needs of toxicokinetic (pharmacokinetic) and toxicology studies. The practice of blood sampling from a variety of rodents using the retrobulbar venous plexus technique is still in common use and suggestions for alternative routes are described because of concerns over the sequelae of using this method.

\section{Circulating blood volumes}

The calculation of limit volumes for blood sampling relies on accurate data on circulating blood volumes. A review of the literature indicates that there is considerable variation in these values, probably relating to the techniques used, the strain and gender of animal, etc. The techniques most frequently cited are radiolabelled erythrocytes, ${ }^{24-26}$ radiolabelled transferrin, ${ }^{27}$ radiolabelled serum albumin, ${ }^{28-30}$ marker dyes, ${ }^{31}$ enzyme dilution, ${ }^{32,33}$ fibre optics ${ }^{34}$ and dextran-70. ${ }^{35}$

Table 3 gives the circulating blood volumes of the species commonly used in safety evaluation studies. Data on the marmoset and minipig, which are becoming more frequently used in toxicology, have now been included. The values shown have been adapted from

Table 3. Circulating blood volume in laboratory animals

\begin{tabular}{lll} 
Species & \multicolumn{2}{c}{ Blood volume $\left(\mathrm{ml} \mathrm{kg}^{-1}\right)$} \\
\cline { 2 - 3 } & $\begin{array}{l}\text { Recommended } \\
\text { mean }\end{array}$ & $\begin{array}{l}\text { Range of } \\
\text { means }\end{array}$ \\
Mouse & 72 & $63-80$ \\
Rat & 64 & $58-70$ \\
Rabbit & 56 & $44-70$ \\
Dog (Beagle) & 85 & $79-90$ \\
Macaque (Rhesus) & 56 & $44-67$ \\
Macaque (Cynomolgus) & 65 & $55-75$ \\
Marmoset & 70 & $58-82$ \\
Minipig & 65 & $61-68$
\end{tabular}

The recommended mean corresponds to the mid-point of the range of means. different sources assuming that the animal is mature, healthy and on an adequate plane of nutrition. ${ }^{23,36-39}$

\section{Blood sampling volumes}

Our recommendations are based on published work, on recent work carried out to inform the working party about certain issues and is being submitted for publication and on information from 'in-house' standard operating procedures.

Animal welfare is a prime consideration when blood sampling is approaching limits but the scientific impact of an animal's physiological response also must be considered because this may affect data interpretation and validity. Assessment of clinical signs shown by the animals, prior to sampling, with referral to supervisory or veterinary staff in doubtful cases, is an expected prerequisite.

Work of Scipioni et al. ${ }^{40}$ indicated that removal of up to $40 \%$ of a rat's total blood volume over $24 \mathrm{~h}$ and repeated 2 weeks later caused no gross ill effects. By and large there are few data on critical aspects of animal well-being after removal of blood, such as heart rate, respiratory patterns, various hormonal levels and behavioural aspects such as activities and time spent carrying them out. All these may change in response to excessive blood removal but it would require considerable effort and resources to investigate them. However, haematological parameters can be measured easily and in a small project ${ }^{41}$ the red blood cell count (RBC), haemoglobin level (HGB), haematocrit (HCT), mean corpuscular volume (MCV) and red cell distribution width (RDW) were measured after the removal of varying blood volumes. Volumes of $7.5 \%, 10 \%, 15 \%$ and $20 \%$ of circulating blood volumes (as 0.3-ml aliquots) were removed from male and female SpragueDawley rats $(n=7)$ weighing ca. $250 \mathrm{~g}$ over a 24-h period to mimic a kinetic study. Animals then were followed for up to 29 days.

The results showed that there was considerable variation in the times taken for all these parameters to return to baseline levels, and in the $15 \%$ and $20 \%$ groups some of the parameters (MCV, RDW) did not return to baseline even after 29 days. The recovery time recommended here for multiple sampling, therefore, is the time taken for all rats in a 'volume' group to return to 'normal' (the starting level for each animal 
Table 4. Limit volumes and recovery periods

\begin{tabular}{|c|c|c|c|}
\hline \multicolumn{2}{|c|}{$\begin{array}{l}\text { Single sampling } \\
\text { (e.g. toxicity study) }\end{array}$} & \multicolumn{2}{|c|}{$\begin{array}{c}\text { Multiple sampling } \\
\text { (e.g. toxicokinetic study) }\end{array}$} \\
\hline $\begin{array}{l}\% \text { Circulatory } \\
\text { blood volume } \\
\text { removed }\end{array}$ & $\begin{array}{l}\text { Approximate } \\
\text { recovery } \\
\text { period }\end{array}$ & $\begin{array}{l}\% \text { Circulatory } \\
\text { blood volume } \\
\text { removed in } \\
24 \mathrm{~h}\end{array}$ & $\begin{array}{l}\text { Approximate } \\
\text { recovery } \\
\text { period }\end{array}$ \\
\hline $7.5 \%$ & 1 week & $7.5 \%$ & 1 week \\
\hline $10 \%$ & 2 weeks & $10-15 \%$ & 2 weeks \\
\hline $15 \%$ & 4 weeks & $20 \%$ & 3 weeks \\
\hline
\end{tabular}

plus or minus 10\%). Single sampling (such as that required for routine toxicity studies) beyond $15 \%$ is not recommended because hypovolaemic shock may ensue if it is not done very slowly. Multiple small samples are unlikely to produce such acute effects.

Table 4 features limit volumes and adequate recovery periods and takes into account the stress of multiple sampling in addition to other procedures in assessing overall severity. The table addresses both single and multiple sampling regimes. Additional recovery time is proposed for animals on toxicity studies because a critical evaluation of haematological parameters is required in such studies.

The higher volume (20\%) is intended to facilitate serial blood sampling for toxico- or pharmacokinetic purposes where multiple, small samples are usually required. However, it should be remembered that the consequential haemodynamic effect of taking such large volumes may well affect the calculated half-life. Assessment of terminal half-life should be possible if final samples are taken within $24 \mathrm{~h}$ of the killing of an animal. These values do not include a terminal sample, which can be taken when the animal is terminally anaesthetized. Blood replacement has not been considered because the volumes proposed do not warrant such intervention.

Using the values from Table 4, an easy reference guide for the volumes that can be removed without significant disturbance to an animal's normal physiology is presented in Table 5.

Table 5. Total blood volumes and recommended maximum blood sample volumes for species of given body weights

\begin{tabular}{|c|c|c|c|c|c|}
\hline Species (weight) & $\begin{array}{l}\text { Blood } \\
\text { volume } \\
\text { (ml) }\end{array}$ & $\begin{array}{l}7.5 \% \\
(\mathrm{ml})\end{array}$ & $\begin{array}{l}10 \% \\
(\mathrm{ml})\end{array}$ & $\begin{array}{l}15 \% \\
(\mathrm{ml})\end{array}$ & $\begin{array}{l}20 \% \\
(\mathrm{ml})\end{array}$ \\
\hline Mouse $(25 \mathrm{~g})$ & 1.8 & 0.1 & 0.2 & 0.3 & 0.4 \\
\hline Rat $(250 \mathrm{~g})$ & 16 & 1.2 & 1.6 & 2.4 & 3.2 \\
\hline Rabbit $(4 \mathrm{~kg})$ & 224 & 17 & 22 & 34 & 45 \\
\hline Dog $(10 \mathrm{~kg})$ & 850 & 64 & 85 & 127 & 170 \\
\hline $\begin{array}{l}\text { Macaque (Rhesus) } \\
(5 \mathrm{~kg})\end{array}$ & 280 & 21 & 28 & 42 & 56 \\
\hline $\begin{array}{l}\text { Macaque } \\
\text { (Cynomolgus) }(5 \mathrm{~kg})\end{array}$ & 325 & 24 & 32 & 49 & 65 \\
\hline Marmoset $(350 \mathrm{~g})$ & 25 & 2.0 & 2.5 & 3.5 & 5 \\
\hline Minipig (15 kg) & 975 & 73 & 98 & 146 & 195 \\
\hline
\end{tabular}

\section{Sampling sites}

Sites for venepuncture and venesection have been considered mainly in rodents and rabbit. ${ }^{23}$ This information has been reviewed in the light of technical advances in blood sampling procedures; the advantages and disadvantages of sites for each species are shown in Table 6, with the recommended ones for repeated sampling summarized in Table 7.

It is important to note that samples taken from different sites may show differences in clinical pathology values and have implications for historical databases. For the more traditional routes, a description of the methodology can be obtained from the standard literature. However, other methods require a special mention and have been reviewed below.

Lateral tarsal (saphenous) vein. This technique has been used in many laboratory animals, including rats, mice, hamster, gerbil, guinea pig, ferret, $\operatorname{mink}^{42}$ and larger animals, and volumes such as $5 \%$ of circulating blood volume may be taken. It does not require an anaesthetic and so is particularly suitable for repeated blood sampling as in pharmacokinetic studies. The saphenous vein is on the lateral aspect of the tarsal joint and is easier to see when the fur is shaved and the area wiped with alcohol. The animal is placed in a suitable restrainer, such as a plastic tube, and the operator extends the hind leg. The vein is raised by gentle pressure above the joint and the vessel is punctured using the smallest gauge needle that enables sufficiently rapid blood withdrawal without haemolysis (e.g. 25-27 g for rats and mice). For small volumes, a simple stab leads to a drop of blood forming immediately at the puncture site and a microhaematocrit tube can be used to collect a standard volume. After blood has been collected, pressure over the site is sufficient to stop further bleeding. Removal of the scab will enable serial sampling.

There appear to be no complications reported other than persistent (minor) bleeding and the method has the advantage that anaesthesia is not required. Even though no studies have been done on animal welfare in terms of body weight gain, diurnal rhythm, behaviour, etc, it seems unlikely that this route will seriously affect an animal's well-being.

Marginal ear vein/central ear artery. Blood sampling from the marginal ear vein is commonly used in rabbits and guinea pigs. This route may also be chosen in minipigs, often combined with the use of an intravenous cannula. Good restraint is necessary and the application of local anaesthetic cream some 20-30 min before bleeding helps to prevent an animal from shaking its head as the needle is pushed through the skin. Bleeds may also be taken by smearing the surface over the vein with petroleum jelly and then puncturing the vein and collecting the blood into a tube. For the removal of larger amounts of blood the central artery in rabbits can be used, but afterwards it must be compressed for at least 2 min to prevent continuing bleeding and haematoma. The animal should be checked for persistent bleeding 5 and 10 min later. Repeated samples can be taken from this artery using an indwelling cannula, thus facilitating a kinetic regimen over $8 \mathrm{~h}$. 
Table 6. Summary of the advantages and disadvantages of the various methods of blood sampling

\begin{tabular}{|c|c|c|c|c|c|}
\hline Route/vein & $\begin{array}{l}\text { General } \\
\text { anaesthesia }\end{array}$ & Tissue damage ${ }^{a}$ & $\begin{array}{l}\text { Repeat } \\
\text { bleeds }\end{array}$ & Volume & Species \\
\hline Jugular & No & Low & Yes & +H & Rat, dog, rabbit \\
\hline Cephalic & No & Low & Yes & +++ & Macaque, dog \\
\hline Saphenous/lateral tarsal & No & Low & Yes & $++(+)$ & Mouse/rat, marmoset/macaque, dog \\
\hline Marginal ear & No (local) & Low & Yes & $\begin{array}{l}++ \\
+\end{array}$ & Rabbit, minipig \\
\hline Femoral & No & Low & Yes & +++ & Marmoset/macaque \\
\hline Sublingual & Yes & Low & Yes & +++ & Rat \\
\hline Lateral tail & No & Low & Yes & $\begin{array}{l}++(+) \\
+\end{array}$ & Rat, mouse/marmoset \\
\hline Central ear artery & No (local) & Low & Yes & +H+ & Rabbit \\
\hline Cranial vena cava & No & Low & Yes & +++ & Minipig \\
\hline Tail tip amputation $(<1-3 \mathrm{~mm})$ & Yes & Mod & Limited & + & Mouse/rat \\
\hline Retrobulbar plexus & Yes & Moderate/high & Yes & +++ & Mouse/rat \\
\hline Cardiac $^{b}$ & Yes & Moderate & No & +++ & Mouse/rat/rabbit \\
\hline
\end{tabular}

aThe potential for tissue damage is based on the likely incidence of it occurring and the severity of any sequelae, e.g. inflammatory reaction or histological damage.

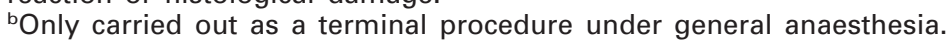

Table 7. Recommended sites for repeated blood sampling

$\begin{array}{ll}\text { Species } & \text { Recommended site } \\ \text { Mouse } & \text { Saphenous, lateral tail } \\ \text { Rat } & \text { Saphenous, lateral tail, sublingual } \\ \text { Rabbit } & \begin{array}{l}\text { Marginal ear, central ear artery, } \\ \text { jugular }\end{array} \\ \text { Dog } & \text { Cephalic, jugular, saphenous } \\ \text { Macaque } & \text { Cephalic, saphenous, femoral } \\ \text { Marmoset } & \text { Femoral, saphenous } \\ \text { Minipig } & \text { Cranial vena cava }\end{array}$

Sublingual vein. This technique is easy to perform in rodents such as rats and is suitable for the removal of large volumes of blood (e.g. $0.2-1 \mathrm{ml}$ ) at frequent intervals, limited only by the blood volume to be removed and by the necessary repeated anaesthesia. A refined method ${ }^{43}$ avoids some of the disadvantages previously seen and can be used for repeated sampling. Rats are anaesthetized and held by an assistant in a supine position. The loose skin at the nape of the neck is gathered up in order to produce partial stasis in the venous return from the head. A second person gently pulls out the tongue with a cotton-tipped applicator stick, grasps it with thumb and forefinger and one of the sublingual veins (there is one on each side of the midline) is punctured with a $23-25 \mathrm{~g}$ hypodermic needle as near to the tip of the tongue as possible. The rat is turned over to allow blood to drip into a tube and after the requisite volume of blood has been obtained the compression at the scruff of the neck is released and the animal is placed in a supine position. The tongue is again extended in order to stem the flow of blood with a dry cotton-tipped applicator stick; usually there is no need to use any haemostatic agent.

With this technique, rats do not show any significant differences in food or water consumption or body weight gain compared with untreated anaesthetized control animals. Moreover, there appear to be fewer pathological changes than with retrobulbar sampling ${ }^{44}$. However, anaesthesia may still be a limiting factor.

Lateral tail vein. In principle this route is similar to the lateral tarsal vein but tends to yield smaller blood volumes $(0.1-0.15 \mathrm{ml}$ in mice; up to $2 \mathrm{ml}$ in warmed rats). Blood is removed either by syringe/needle or stab puncture of a lateral tail vein. Anaesthesia is unnecessary, which makes this route particularly suited for repeated blood sampling. Vasodilatation may be necessary to promote bleeding and can be caused by exposing an animal to $37^{\circ} \mathrm{C}$ for $5-8 \mathrm{~min}$ or by local warming of the tail. There appear to be few disadvantages that affect animal well-being, but animals must be closely monitored for signs of distress if heat exposure is used.

Cranial vena cava. Minipigs may be restrained in a sling or on their backs with the forelegs retracted caudally. Other methods, sometimes used in agricultural settings (snout tying, hog tying, suspending animals by their rear legs), are stressful and are inappropriate for laboratory animals because of the potential adverse effects on the science. In order to avoid injury to the vagus nerve, the needle is inserted into the right side of the neck, lateral to the manubrium sterni, and directed at a $30-45^{\circ}$ angle towards the left shoulder. A popping sensation will be felt by the sampler when the needle enters the vein, and then blood can be readily withdrawn. This method can also be utilized for sequential venipuncture but haematomas form in the area after the needle is withdrawn, therefore it is best reserved for procedures that do not require withdrawal more often than weekly. ${ }^{45}$

Amputation of the tail tip. This technique is commonly used in rats and mice, with sample volumes of $0.1-0.2 \mathrm{ml}$ being obtained. Amputation should be restricted to the tail tip $(0.5-1 \mathrm{~mm}$ should be adequate, and over time a maximum of $5 \mathrm{~mm}$ can be removed) and repeat bleeding is feasible in the short term by 
removing the clot. Serial amputations resulting in a significant shortening of the tail (i.e. $>5 \mathrm{~mm}$ ) are not acceptable. The technique may not be suitable for older animals. Anaesthesia is recommended.

Cardiac puncture. This should always be carried out under general anaesthesia and in the past it has been used with recovery in small rodents due to the lack of alternative routes. However, other methods are now available and because of potentially painful and fatal sequelae, such as pericardial bleeding and cardiac tamponade, this technique should only be used for terminal bleeds.

Retrobulbar plexus. The retrobulbar route has been commonly used by researchers in the past but has been observed to cause adverse effects. Concern has therefore arisen because of these effects and their potential severity. Recently, however, other methods have been developed that meet the scientific requirements and also improve the welfare of the animals. Nevertheless, the Technical Subgroup felt that it was worth reviewing in detail some of the advantages and disadvantages of retrobulbar bleeding in the context of the new methods.

Bleeding from this plexus always should be carried out under general anaesthesia in all species and anaesthesia is a requirement in some national regulations. The method has been described in detail by a number of workers. ${ }^{46-48}$

There is little published work on refining the method. The approach (lateral or access via the dorsal or upper aspect of the eye in rats) as the optimal way to penetrate the conjunctiva in order to minimize tissue damage has been discussed. ${ }^{23}$ An interval of 2 weeks between bleeds at the same site should allow damaged tissue to repair in most cases, ${ }^{49}$ but this does not mean that the animals do not experience some discomfort during the early stages before healing is complete; there are, however, concerns over repeated retrobulbar punctures. Whereas some studies have shown that repeated orbital bleeds do not affect the animals' diurnal rhythm $\mathrm{m}^{50,51}$ or the histology of the orbital tissue long term ${ }^{52,49}$ (i.e. both showed that any tissue damage healed), other studies have found histological changes, abnormal clinical signs and evidence of discomfort ${ }^{53-55}$ which has led to animals having to be killed on humane grounds and so lost from the study. There are also other serious potential adverse effects:

(i) retrobulbar haemorrhage resulting in haematoma and excessive pressure on the eye, which is almost certainly painful for the animal;

(ii) any pressure required to stem persistent bleeding (e.g. by pressing on the eye) or pressure from a haematoma can lead to corneal ulceration, keratitis, pannus formation, rupture of the globe and micro-ophthalmia;

(iii) damage to the optic nerve and other intra-orbital structures, which can lead to deficits in vision and even blindness;

(iv) fracture of the fragile bones of the orbit and neural damage by the micropipette; and penetration of the eye globe itself with a loss of vitreous humour.

Many of these unwanted sequelae may stay undetected, being located deep within the orbit. The incidence of unwanted side-effects appears to vary between $1 \%$ and $2 \%,{ }^{52}$ but may be far higher in the hands of some technicians, even though they were experienced (see table 1 of Ref. 55).

\section{Frequency of needle punctures}

It is important to carry out the minimum number of needle punctures consistent with obtaining good scientific data. The same puncture site should not be used, i.e. use different points along a vein.

\section{Cannulation}

This is an important technique for repeated bleeds. Temporary cannulae such as butterfly needles and overthe-needle cannulae can be used in the short term (working day), whereas for long-term use surgical implantation of biocompatible cannulae is required. These methods allow repeated blood sampling with minimal distress and discomfort for the animal. The use of subcutaneous venous access ports is also useful because it allows an implanted animal to stay with its peers, but there are a number of potential problems that must be addressed:

(i) Surgical skills are essential and it must be done in a sterile way for good long-term performance ${ }^{56}$ and to avoid complications such as infection. Clotting frequently occurs and may prevent both blood removal and prolonged infusion of substances.

(ii) It may be necessary to restrain an animal or to separate it from its peers in order to prevent removal or biting of the attached external cannulae, which is why a subcutaneous venous access port is preferred in the long term.

(iii) After long-term cannulation, penetration of the vessel can occur and an animal may also outgrow its cannula.

\section{Anaesthesia}

Some comments on how various anaesthetics affect the muscle cells in the splenic capsule (if present) are given in the first report of the BVA/FRAME/ RSPCA/UFAW, ${ }^{23}$ as well as other aspects of promoting blood withdrawal. In relation to the removal of blood from small laboratory mammals, it is worth noting that the combination of fentanyl and fluanisone (Hypnorm), with or without midazolam (Hypnovel), causes a significant peripheral vasodilatation in all species. Although this makes taking blood samples easier, it also makes post-sampling haemorrhage more likely and so particular attention must be paid to ensuring haemostasis. Consideration should be given to the use of local anaesthetics.

\section{Conclusion and recommendations}

There is now a range of alternative methods for the removal of blood from all species of animals, particularly the smaller rodents where in the past it has not been easy. Furthermore, some methods require an anaesthetic or have a higher incidence of unwanted 
side-effects that may seriously affect an animal's welfare, particularly when repeat bleeding is required. We therefore recommend that:

(i) recommended routes for bleeding are the lateral tail vein, the sublingual vein and the lateral tarsal vein for all rodents, and the marginal ear vein, central ear artery and the jugular vein for rabbits;

(ii) retrobulbar sampling with recovery should be used only when other routes are not practical;

(iii) sampling by cardiac routes is only carried out as a terminal procedure under general anaesthesia.
Finally, we wish to emphasize that, as in all experimental procedures involving animals, thorough training and competence of personnel is crucial for successful bleeding, minimizing tissue damage and also for the health and welfare of the animals.

\section{Acknowledgements}

The Technical Subgroup wishes to thank those who responded to this document with valuable comments. These have been incorporated where possible.

\section{REFERENCES}

1. EU Council Directive 86/609/EEC of 24 November 1986 on the approximation of laws, regulations and administrative provisions of the Member States regarding the protection of animals used for experimental and other scientific purposes. Off. J. Eur. Commun. 1986; 29: L358, 1-29.

2. Hull RM. Guideline limit volumes for dosing animals in the preclinical stage of safety evaluation, Hum. Exp. Toxicol. 1995; 14: 305-307.

3. Flecknell P. Laboratory Animal Anaesthesia (2nd edn). Harcourt Brace and Company: London 1996.

4. Wolfensohn S, Lloyd M. Procedural data. In: Handbook of Laboratory Animal Management and Welfare, Wolfensohn S, Lloyd M (eds). Oxford University Press: Oxford, 1998.

5. Hejgaard KC, Alban L, Thomsen P, Heller KE, Hansen AK. Assessing welfare of rats undergoing gavaging with varying volumes. Measurements on open field behaviour, temperature, plasma corticosterone and glucose [Abstract]. Rev. Cienc. 1999; 23/24: 16.

6. Vermeulen JK, De Vries A, Schlingmann F, Remie R. Food deprivation: common sense or nonsense? Anim. Technol. 1997; 48: 45-54.

7. Claassen V. Neglected factors in pharmacology and neuroscience research. In Techniques in the Behavioural and Neural Sciences, vol. 12, Huston JP (ed.). Elsevier: Amsterdam, 1994: 5-94.

8. Zeoli A, Donkin H, Crewell C, Fetrow N, Johnson DK, Kinter LB. A limit rapid intravenous injection volume in dogs [Abstract]. Toxicol Sci. 1998; 42: 58.

9. Morton D, Safron JA, Rice DW, Wilson DM, White RD. Effects of infusion rates in rats receiving repeated large volumes of saline solution intravenously. Lab. Anim. Sci. 1997; 47: 656-659.

10. Morton D, Safron JA, Glosson J, Rice DW, Wilson DM, White RD. Histologic lesions associated with intravenous infusions of large volumes of isotonic saline solution in rats for 30 days. Toxicol. Pathol. 1997; 25: 390-394.

11. McKeon ME, Walker MD, Wakefield AE, Machotka SV. Validation of infusion techniques in nonpregnant and pregnant rabbits using a novel harness system [Abstract]. Toxicol. Sci. 1998; 42: 292.

12. Cave DA, Schoenmakers ACM, van Wijk JH, Enninga IC, Van der Hoeven JCM. Continuous intravenous infusion in the unrestrained rat-procedures and results. Hum. Exp. Toxicol. 1995; 14: 192-200.

13. Barrow PC, Heritier B. Continuous deep intravenous infusion in rat embryotoxity studies: the effects of infusion volume and two different infusion fluids on pregnancy. Toxicol. Methods 1995; 5: 61-67.

14. Loget O, Nanuel C, Le Bigot J-F, Forster R. Corneal damage following continuous infusion in rats. In Advances in Ocular Toxicology, Green, Edelhauser HF, Hackett RB, Hull DS, Potter DE (eds.). Plenum Press: New York, 1997; 55-62.

15. Van Wijk H. A continuous intravenous infusion technique in the unrestrained mouse. Anim Technol. 1997; 48: 115128.

16. Perkin CJ, Stejskal R. Intravenous infusion in dogs and primates. J Am. Coll. Toxicol. 1994; 13: 40-47.
17. Cornelius LM, Finco DR, Culver DH. Physiologic effects of rapid infusion of Ringer's Lactate solution into dogs. Am. J. Vet. Res. 1978; 39: 1185-1190.

18. Concannon KT, Haskins SC, Feldman BF. Hemostatic defects associated with two infusion rates of dextran 70 in dogs. Am. J. Vet. Res. 1992; 53: 1369-1375.

19. Manenti A, Botticelli A, Buttazzi A, Gibertini G. Acute pulmonary edema after overinfusion of crystalloids versus plasma: histological observations in the rat. Pathologica 1992; 84: 331-334.

20. Mann WA, Kinter LB. Characterization of maximal intravenous dose volumes in the dog (Canis familiaris). Gen. Pharmacol. 1993; 24: 357-366.

21. Leenars PPAM. Adjuvants in Laboratory Animals (Synopsis of $\mathrm{PhD}$ thesis and publications). Ponsen and Looijen BV: Wageningen, 1997.

22. Leenars PPAM, Koedam MA, Wester PW, Baumans V, Claassen E, Hendriksen CFM. Assessment of side-effects induced by injection of different adjuvant/antigen combinations in rabbits and mice. Lab. Anim. 1998; 32: 387-406.

23. First report of the BVA/FRAME/RSPCA/UFAW, Joint working group on refinement removal of blood from laboratory mammals and birds. Lab Anim. 1993; 27: 1-22.

24. Smith BSW. Comparison of iodine-125 and chromium- 51 for measurement of total blood volume and residual blood content of tissue in the rat; evidence for accumulation of 51Cr by tissues, Clin. Chim. Acta 1970: 27: 105-108.

25. Sluiter W, Oomens LWM, Brand A, Van Furth R. Determination of blood volume in the mouse with chromium51-labeled erythrocytes. J. Immunol. Methods 1984; 73: 221-225.

26. Fujii A, Yoshikawa K, Iwata T, Akashi M, Noguchi $H$, Takumi Y. A method for measurement of circulating blood volume with fluorescein isothiocyanate labeled red blood cells. Jpn. Anesthesiol. 1993; 42: 545-551.

27. Argent NB, Liles J, Rodham D, Clayton CB, Wilkinson $R$ Bayliss PH. A new method for measuring the blood volume of the rat using $113 \mathrm{~m}$ Indium as a tracer. Lab. Anim. 1994; 28: 172-175.

28. Carvalho JS. Heterologous serum albumin as tracer for plasma volume measurements evaluated in conscious nondehydrated and 48-hour water-deprived rats. Cardiovasc. Pharmacol. 1989; 13: 603-607.

29. Gillen CM, Takamata A, Mack GW, Nadel RE. Measurement of plasma volume in rats with use of fluorescentlabeled albumin molecules. Appl. Physiol. 1994; 76: 485489.

30. Callahan RJ, Wilkinson RA, Bogdonov Jr AA. Validation of plasma volume determinations in the rat using an In111 labeled polymer and I-125 human serum albumin. 42nd Annual Meeting of the Society of Nuclear Medicine, Minneapolis, Minnesota, USA, June 12-15, 1995. Nucl. Med. 1995; 36: 157-158.

31. Schad H, Haider M, Brechtelsbauer $H$. Determination of plasma volume with indocyanine green. Anesthetist 1987; 36: 608-614.

32. Visser MP, Krill MTA, Willems GM, Hermens TW. Plasma volume determination by use of enzyme dilution in the dog. Lab. Anim. 1982; 16: 248-255. 
33. Holmes MA, Weiskopf RB. Determination of plasma volume in swine by the enzyme-dilution method. Am. J. Physiol. 1987; 252: 1003-1008.

34. Kisch H, Leucht S, Lichtwarck AM. Accuracy and reproductivity of the measurement of actively circulating blood volume with an integrated fiberoptic monitoring system. Crit. Care Med. 1995; 23: 885-893.

35. Van-Kreel BK, van-Beek E, Spaanderman MEA, Peeters LL. A new method for plasma volume measurements with unlabeled dextran-70 instead of 125l-labeled albumin as an indicator. Clin. Chim. Acta 1998; 275: 71-80.

36. Altman PL, Dittmer DS. Biology Data Book (2nd edn), vol. 3. Altman PL, Dimmer DS (eds). Federation of American Societies of Experimental Biology: Bethesda, MD, 1974.

37. Swenson MJ. Dukes' Physiology of Domestic Animals (9th edn). Ithaca London Comstock: Ithaca, (1977).

38. Jain N. Schalm's Veterinary Haematology (4th edn). Lea and Febiger: Philadelphia, 1986.

39. McGuill MW, Rowan AN. Biological effects of blood loss: implications for sampling volumes and techniques. ILAR News 1989; 31: 5-18.

40. Scipioni RL, Diters RW, Myers WR, Hart SM. Clinical and clinicopathological assessment of serial phlebotomy in the Sprague Dawley rat. Lab. Anim. Sci. 1997; 47:293-299.

41. Nahas K, Provost J-P, Baneux P, Rabemampianina $Y$. Effects of acute blood removal via the sublingual vein on haematological and clinical parameters in Sprague-Dawley rats, Laboratory Animals 2000, 34, 362-371.

42. Hem A, Smith J, Solberg P. Saphenous vein puncture for blood sampling of the mouse, rat, hamster, gerbil, guinea pig, ferret and mink. Lab. Anim. 1998; 32: 364-368.

43. Zeller $W$, Weber $H$, Panoussis B, Bürge $T$, Burgmann $R$. Refinement of blood sampling from the sublingual vein of rats. Lab. Anim. 1998; 32: 369-376.

44. Mahl $A$, Heining $P$, Ulrich $P$, Jakubowski J, Bobadilla $M$ Zeller W, Bergmann R, Singer T, Meister L. Comparison of clinical pathology parameters with two different blood sampling techniques in rats - retrobulbar plexus versus sublingual vein, Laboratory Animals, 2000, 34, 351-361.

45. Swindle MM. Surgery, anesthesia, and experimental techniques. In Swine. lowa State University Press: Ames, 1998: $1-329$.
46. Stone SH. Method for obtaining blood from the orbital sinus of the rat or mouse, Science 1954; 119: 100.

47. Waynforth HB, Flecknell PA. Methods of obtaining body fluids. In Experimental and Surgical Technique in the Rat. Academic Press: London, 1992; 68-88.

48. Van Herck H. Orbital puncture: a non-terminal blood sampling technique in rats. PhD Thesis, University of Utrecht, 1999.

49. Van Herck $H$, Baumans $V$, Van der Craats NR, Hesp AP, Meijer Gw, Van Tintelen G, Walvoort HC, Beynen AC. Histological changes in the orbital region of rats after orbital puncture. Lab. Anim. 1992; 26: 53-58.

50. Beynen C, Baumans V, Haas JWM, Van Hellemond KK Stauflau FR, Van Tintelen G. Assessment of discomfort induced by orbital puncture in rats. In New Developments in Biosciences: their Implications for Laboratory Animal Science, Beynen AC, Solleveld HA (eds). Martinus Nijhoff: Dordrecht, NL, 1988; 431-436.

51. Van Herck H, De Boer SF, Hesp APM, Van Lith HA, Baumans $\mathrm{V}$, Beynen AC. Orbital bleeding in rats while under diethylether anesthesia does not influence telemetrically determined heart rate, body temperature, locomotor activity and eating activity when compared with anesthesia alone. Lab. Anim. 1997; 31: 271-278.

52. Krinke A, Kobel W, Krinke G. Does the repeated orbital sinus puncture alter the occurrence of changes with age in the retina, the lens, or the Harderian gland of laboratory rats? Z. Versuch. 1988; 31: 111-119.

53. McGee N, Maronpot RR. Harderian gland dacryoadenitis in rats resulting from orbital bleeding. Lab. Anim. Sci. 1979; 29: 639-641.

54. Le Net JEL, Abbott DP, Mompon RP, Leblanc B. Repeated orbital sinus puncture in rats induces damages to optic nerve and retina. Vet. Pathol. 1994; 31: 621.

55. Van Herck H, Baumans V, Brandt CJWM, Hesp AP, Sturkenboom JH, Van Lith HA, Van Tintelen G, Beynen AC. Orbital sinus blood sampling in rats as performed by different animal technicians: the influence of technique and expertise. Lab Anim. 1998; 32: 377-386.

56. Popp MB, Brennan MF. Long-term vascular access in the rat: importance of asepsis. Am. J. Physiol. 1981; 241: 606-612. 